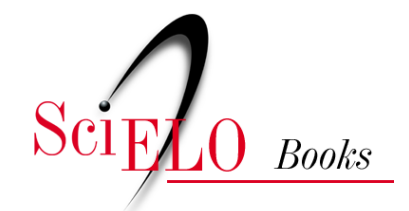

\title{
III. Poéticas
}

Entre meios... linhas, tessituras, práticas e agenciamentos de um estudante e seu professor mediador

\author{
Luan Sávio
}

\section{SciELO Books / SciELO Livros / SciELO Libros}

SÁVIO, L. Entre meios... linhas, tessituras, práticas e agenciamentos de um estudante e seu professor mediador. In: RIBETTO, A., org. Professores formados na FFP/UERJ e inclusão: entre políticas, práticas e poéticas (online). Rio de Janeiro: EDUERJ, 2018, pp. 217-235. ISBN 978-85-7511-502-2. Available from: doi: $10.7476 / 9788575115022.0013$. Also available in ePUB from: http://books.scielo.org/id/dpg28/epub/ribetto-9788575115022.epub.

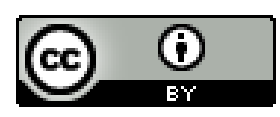

All the contents of this work, except where otherwise noted, is licensed under a Creative Commons Attribution 4.0 International license.

Todo o conteúdo deste trabalho, exceto quando houver ressalva, é publicado sob a licença Creative Commons Atribição $\underline{4.0}$.

Todo el contenido de esta obra, excepto donde se indique lo contrario, está bajo licencia de la licencia $\underline{\text { Creative Commons }}$ Reconocimento 4.0. 


\title{
Entre meios... linhas, tessituras, práticas e agenciamentos de um estudante e seu professor mediador
}

\author{
LUAN SÁVIO
}

Este texto é um movimento de escrita que faz emergir minha primeira experiência profissional como egresso da Faculdade de Formação de Professores da UERJ. O objetivo é analisar a mediação escolar feita entre o pedagogo e seu aluno autista. O esforço presente circunda a seguinte questão: Que práticas fazem mais bela e poética a relação entre mediador e mediado na educação especial? Para tal, criarei um mapa sobre o decalque dos diários de campo que produzi como mediador, para acompanhar e avaliar o trabalho pedagógico.

\section{Linhas iniciais...}

Eis aqui um movimento de escrita que é a análise de minhas implicaçôes como pedagogo, que labora numa escola, pela primeira vez, depois de formado, sendo professor mediador de um estudante diagnosticado como autista em um grau severo. Inicialmente, o aluno apresentava-se como uma criança cuja comunicação verbal era considerada desfavorável, com pouquíssima autonomia para realizar tarefas cotidianas, tais como usar o banheiro, arrumar-se ou abrir uma garrafa de refrigerante.

Como professor, um egresso inexperiente, com alguma sapiência advinda de textos acadêmicos ou de vídeos da internet, quanto aos vários tipos de público da Educação Especial, a profissão de 
professor mediador tornou-se um desafio profissional intimidador. Inspirado na filosofia de Deleuze e Guattari (20II), trago minha experiência registrada, muitas vezes, decalcada, acerca do meu trabatho para, sobre ele, desenhar uma cartografia. Ou seja, um mapa:

aberto, conectável em todas as suas dimensôes, desmontável, reversível, suscetível de receber modificaçóes constantemente. Ele pode ser rasgado, revertido, adaptar-se a montagens de qualquer natureza, ser preparado por um indivíduo, um grupo, uma formação social. Pode-se desenhá-lo numa parede, concebê-lo como obra de arte, construí-lo como ação política, ou como uma meditação (Deleuze e Guattari, 20II, p. 30).

A potência das transformaçóes na prática pedagógica fincada aqui é o que delineia a ação de cartografar, "enquanto no método cartesiano buscamos nos desvencilhar de nós mesmos para abarcar a universalidade de um sujeito epistêmico geral" (Costa et al., 20I2, p. 47). Aqui reconheço que estou imbricado, construído e atravessado por uma rede infinita que me faz operar, na qual também sou criador de um modo de fazer educação escolar.

Percebo a variedade de possibilidades pedagógicas, mesmo quando tateio. Ora, "Um mapa tem múltiplas entradas contrariamente ao decalque que volta sempre 'ao mesmo" (Deleuze e Guattari, 20II, p. 30). O caminho ou a rota de entrada aqui será o momento de transição entre graduando e egresso.

\section{Pequeno relato de um Pinóquio antes de ser professor mediador}

Sou egresso do curso de Pedagogia da Faculdade de Formação de Professores - FFP, da UERJ', em São Gonçalo. Ainda que seja

I. Universidade do Estado do Rio de Janeiro. 
difícil dizer a respeito de todos os detalhes de cada um dos semestres de graduação, são preciso deixar claro que os modos como se habita a universidade é sempre peculiares, particulares, múltiplos e também regidos por certo consenso.

É comum cursar disciplinas curriculares e não ler os textos pedidos pelos professores. Náo cumprir com prazos de entrega dos trabalhos acadêmicos solicitados é táo corriqueiro quanto chegar atrasado às aulas (por $n$ motivos), ou assinar a presença e sair da sala - muitos chamam isso de "deixar a mochila assistindo à aula".

Ainda há mais um estigma: é comum se ouvir pelos corredores da faculdade que a graduação em Pedagogia é simplória. Ninguém é reprovado e só aprendemos a reproduzir o que todo mundo já sabe, desde a educação infantil até o final do primeiro segmento da educaçáo básica, e que o graduando desse curso estuda menos que aqueles das outras licenciaturas. A questão não é generalizar o breve exposto, nem desmentir, mas endossar a "escolha ético-estético-política ${ }^{2}$, no que diz acerca dos modos como habito um lugar, que foi produto de tantos movimentos e produziu outras formas de existir" (Sávio, 20I2, p. 4).

Apesar do consenso e do estigma nebuloso que marca o alunato da FFP, pude ver, durante o tempo em que estive no referido espaço, muitas supernovas que afirmavam o próprio lugar. Era como se surgissem Pinóquios que negavam tal verdade obscura que se instituiu.

Eram tantos os Pinóquios, dedicando-se aos grupos de pesquisa, investindo horas refinando a escrita, saindo às pressas da FFP para o trabalho e lendo no ônibus, trocando o descanso, a folga e o lazer pelo estudo, que era como se os narizes grandes de madeira

2. O ético-estético-político estabelece como compromisso a afirmação da vida, em que "a ética é o reconhecimento da diferença, a estética faz referência ao processo de criação da existência e a política afirma os compromissos e os riscos das práticas implicadas" (Nascimento e Scheinvar, 20IO, pp. 25-6). 
esbarrassem uns nos outros. Diversas alianças e amizades se consolidavam durante a graduação.

Além de batalharmos contra a procrastinação para qualificar a graduação, muitos de nós fazíamos o movimento estudantil por meio do centro acadêmico de estudantes: conseguíamos, junto aos docentes, aumentar a oferta de horários das disciplinas curriculares; orientávamos e arregimentávamos outros colegas; organizávamos eventos acadêmicos e palestras; garantíamos representação estudantil nos colegiados da FFP; e, quando possível, estávamos presentes nas audiências públicas para a educação na cidade.

A graduação para os Pinóquios era extenuante, mas viva, alegre e engajada; possível, intensa e de algum jeito fugaz. Logo estava com a monografia pronta, entregue e com um certificado de conclusão de curso. Foi quando me tornei egresso que entendi como é difícil ser professor no primeiro segmento. Na rede privada, existe uma ressalva em contratar homens. Ainda há muito machismo nos certames educacionais. Um paradoxo, pois, geralmente, à frente das turmas, está uma mulher.

Enquanto estudava para fazer concursos públicos, deixava currículos e não tinha o retorno. Porém, em um dia de janeiro, próximo ao início do ano letivo, uma colega (um desses Pinóquios da graduação) ligou-me dizendo de um processo seletivo em uma escola para ser mediador de um estudante autista. Ela, que não era da minha turma, sabia do meu interesse pela Educação Especial porque fizemos um curso de extensão ${ }^{3}$, na FFP, acerca do tema.

Além de participar da seleção feita pela equipe gestora da escola, conversei com a família da criança. Minha contratação ocorrera, principalmente, porque o discente a ser mediado era um rapaz,

3. O curso coordenado pela Prof. ${ }^{a}$ Dr. $^{a}$ Anelice Ribetto (FFP/UERJ) era: "Diferenças e alteridade na Educação: pensando a interface Educação Especial - Escola Inclusiva”. 
e a referência masculina do mediador, em muitos casos, é bem aceita e sugerida por especialistas.

\section{As linhas do teceláo: uma pedagogia da mediaçáo escolar}

Bosquejo um movimento de escrita que venha à tona, para pensar a minha inserçáo profissional, no ano de 2013, que acontecera por meio de uma experiência de Atendimento Educacional Especializado. Nessa experiência, cabia a mim, na condição de professor mediador, possibilitar a inclusão do aluno no segundo ano do ensino fundamental. Como mediador escolar, minhas atribuiçóes eram: adaptar o currículo e possibilitar maior autonomia enquanto circula/utiliza os espaços da escola.

Alguns exemplos de atividades: pinturas em diversas texturas (lixas, papel, tela, entre outros); pareamentos com as letras do nome ou cores básicas; exercícios de coordenação motora fina e grossa; movimento de pinça e lateralidade. Buscava realizar comunicaçáo alternativa por meio da troca de imagens e de sua rotina, que era fotografada. Havia o momento para a experimentaçáo de instrumentos musicais e argila. Muitas tarefas não me foram dadas a priori, não estavam lá desde sempre à espera de alguém que a executasse. Já outras, eram demandas sedimentadas. A labuta inicial foi o engendramento e a organização de um conjunto de propostas que poderiam ou não funcionar naquele contexto.

Assim, em fevereiro de 2013, iniciei um trabalho que era também o começo da minha prática profissional no campo da educação, a saber: mediaçáo escolar em uma escola privada. Um cargo que náo existe, e que traz consigo a potência de ser o que quiser devido a uma não definição, ou seja, os vínculos profissionais são sempre delicados, já que náo se assina a carteira de um mediador. $\mathrm{Na}$ rede pública, há tempos, alguns concursos têm feito aparecer professores de apoio especializado ou educação especial graças às 
leis de inclusão. Mediar o quê? Especializado para qual serviço? Especial pressupóe que formação?

Quando adentrei a escola, um sentimento de "O que é isso que se passa?" foi persistente. E cruzava os portóes o jovem estudante que seria mediado por mim... Tais perguntas trazem consigo um emaranhado de situaçóes que colocarei em evidência. A prática profissional, tal como a pesquisa cartográfica, é "encontrar-se com reentrâncias fugidas de dimensóes mínimas que abrem problemáticas ilimitadas" (Costa et al., 20I2, p. 47), e ambas dizem respeito a uma implicaçâo e a um arcabouço teórico-metodológico que norteou e constituiu práticas. Portanto, proponho aqui não uma resposta, mas fazer das perguntas um tear. E, das possibilidades, potências que tornem as pedagogias não formas prontas, concretas e indubitáveis, mas linhas que, nesse caso, são "máquinas de fazer ver e de fazer falar” (Deleuze, I990, p. I) minhas trajetórias nesse trabalho pedagógico. Como se as problematizaçôes pudessem ser puxadas num tapete formado de experiências que se elaboram.

O exercício de escrita presente será um encontro com contos e poesias. As leituras de literatura funcionam "como jornadas, como viagens a lugares diferentes, a outras cabeças e formas de pensar e de ver o mundo. Como abertura, como portas para outros mundos e para outros olhares" (Cabral, 2006, p. 4). "A literatura é um agenciamento" (Deleuze e Guattari, 20II, p. 19) para a transformação dos modos de estar no mundo. Aqui, em especial, de perceber a docência na Educação Especial por meio de um procedimento da escrita. Os poemas e textos literários seráo constitutivos da estética deste texto, que trata do encontro belo e imprevisível entre um pedagogo e a criança mediada por ele.

Acordava ainda no escuro, como se ouvisse o sol chegando atrás das beiradas da noite. E logo sentava-se ao tear. Linha clara, para começar o dia. Delicado traço cor de luz, que ela ia passando entre os fios estendidos, en- 
quanto lá fora a claridade da manhã desenhava o horizonte. Depois lâs mais vivas, quentes lấs iam tecendo hora a hora, em longo tapete que nunca acabava. Se era forte demais o sol, e no jardim pendiam as pétalas, a moça colocava na lançadeira grossos fios cinzentos de algodão mais felpudo. Em breve, na penumbra trazida pelas nuvens, escolhia um fio de prata, que em pontos longos rebordava sobre o tecido. Leve, a chuva vinha cumprimentá -la à janela (Colassanti, 20I4, p. ?).

A moça tecelá nos ajuda a colocar em análise as linhas, náo na idealização de um "era uma vez", mas como condição de uma existência em um plano vivo, real, concreto, tangível e palatável. Assim, ela acordava todos os dias para tecer sua vida. Suas expectativas, seus sonhos, o desejo de um dia nublado ou ensolarado, sua fome, a paisagem que contemplava, sua carência, tudo passava por seu exercício de formar um tapete sem fim. O fazer docente se constitui no transcurso de cada período letivo, em meio ao planejamento, às aulas, ao local de trabalho, enfim, ao cotidiano da escola.

"É assim, jogando a lançadeira de um lado para outro e batendo os grandes pentes do tear para frente e para trás, a moça passava os seus dias" (Colassanti, 20I4, p. I). Os sentidos conferidos aos fazeres na educação estão imbricados com dualismos que insistem em reinar e que insisto em desfazer, tais como: vida profissional-vida pessoal, ensino-aprendizagem, teoria-prática... O tapete remete à ideia de uma multiplicidade náo cartesiana das partes divisíveis, localizáveis e indexadas, mas que se misturam, confundem-se, dando tons a paisagens, objetos, sentimentos... Deslocados aqui por meio de uma prática pedagógica singular, histórica e pontual.

O traçado das linhas que faço evidente afirmou-se desde o primeiro encontro com o rapaz. Lancei mão de um procedimento sistemático de registro escrito, os diários de campo, feitos para acompanhar e avaliar o trabalho e o desenvolvimento do aluno em 
voga, o qual especificarei adiante. Ao mesmo tempo, serviu como estofo para as palavras a seguir. Valendo-me de tais registros datados, farei aparecer, na descrição de algumas experiências, analisadores das minhas práticas nessa experiência na Educação Especial.

$\mathrm{O}$ que fazer? Por qual caminho andar? Como mediar sua estada na escola? De que maneira significar seus gestos? Tais perguntas emergem no encontro entre o menino e eu. Eclodem de forma repentina quando me deparo com uma situação nova na escola ou quando o rapaz me surpreende com uma ação. Grudam na mente $\mathrm{e}$, às vezes, nem tiram pausa para dormir. As perguntas movem o fazer pedagógico e dão potência à diferença. Por isso, agradam-me as incertezas - elas apontam para outras saídas e desdobramentos.

Fui me dando conta da estrutura que já estava em torno de uma criança diagnosticada com um grau severo de autismo, com regras rígidas, medos, limites já estabelecidos, e entrava ali para seguir com um planejamento dado de antemão.

Dias e dias, semanas e meses trabalhou a moça tecendo tetos e portas, e pátios e escadas, e salas e poços. A neve caía lá fora, e ela não tinha tempo para chamar o sol. A noite chegava, e ela não tinha tempo para arrematar o dia. Tecia e entristecia, enquanto sem parar batiam os pentes acompanhando o ritmo da lançadeira (Colassanti, 20I4, p. I).

Eu era um pedagogo inábil, e a impressão que tinha era de que o rapaz não aprendia. Ao contrário, o cenário que percebia era de que o menino mais se fechava para o mundo e, naquela altura, o tear era signo de rigidez, como a do marido que obrigava a moça a tecer algo que náo a agradava. Como aquela tecelá que trançava as linhas, fui dominado por inquietaçóes que, de algum jeito, faziam com que mantivesse a regularidade do diário ${ }^{4}$. Ressalto que esse

4. A escrita diária dos mínimos gestos e da rotina era a ferramenta utilizada para registro do óbvio, do cotidiano, dos microavanços e grandes retrocessos, ou vice-versa. Por meio dele, monta- 
foi um método de trabalho possível que concebi - não estou dando a saída salvadora para todos os dramas da docência. Os pequenos gestos cotidianos foram descritos em um caderno que se tornara um instrumento fundamental.

Desta vez não precisou escolher linha nenhuma. Segurou a lançadeira ao contrário, e, jogando-a veloz de um lado para o outro, começou a desfazer o seu tecido. Desteceu os cavalos, as carruagens, as estrebarias, os jardins. Depois desteceu os criados e o palácio e todas as maravilhas que continha. E novamente se viu na sua casa pequena e sorriu para o jardim além da janela (Colassanti, 20I4, p. 2).

Paulatinamente, desfazia as linhas de uma identidade autista que encrustavam o rapaz. Não que ele deixaria de ser autista, tratava-se de deslocar algumas verdades produzidas acerca do rapaz, como se não fosse possível mudar ou, ao menos, derrubar, enquanto estávamos juntos, as suas hierarquias. Por exemplo, diziam que ele era agressivo, mal humorado e que os remédios eram sempre fundamentais. Foram destrançadas algumas verdades absolutas que regiam a vida do discente.

Desse modo, tento dar cor e sentido ao que sinto e acontece com ele e comigo, em interseção com sua família e a escola, dia após dia. E, assim, esperava irromper as formas cristalizadas que aprisionavam nosso amigo e sua relação com as desaprendizagens desse mundo cinza e duro. O olhar do rapaz, carregado de intencionalidade, e suas expressóes dizem muito a respeito do que quer. O jeito como trabalhavámos também carregava significados. Denotava que, em alguns momentos, contemplamos e, em outros, somos contemplados, tal como a obra de arte e o artista, que quase não podemos discernir "quem é qual". 
Significa dizer que, em muitos momentos, eu podia entender o que o rapaz queria e que estava angustiado por um brinquedo ou para sair da sala. Isso náo era evidente para mim no começo do trabalho. Uma troca no medicamento poderia mudar o humor, por exemplo, e isso também era sempre uma novidade para mim. Os momentos de circular pelos espaços da escola, que materiais usar e as atividades propostas não eram algo impossível de mudar, haja vista que o educando nunca estava completamente adaptado - como se isso fosse possível.

Com a ajuda da coordenação da escola, da minha supervisora de Educação Especial, da professora regente e da família, tateávamos para descobrir outras rotinas que não desestabilizassem o rapaz. Ao mesmo tempo, eu era observado e avaliado e estava à prova se todo o planejamento funcionava. Minha presença também fora sentida como grande novidade.

"Então, como se ouvisse a chegada do sol, a moça escolheu uma linha clara. E foi passando-a devagar entre os fios, delicado traço de luz, que a manhã repetiu na linha do horizonte" (Colassanti, 20I4). O sutil para alinhavar tudo que pode ser anotado, registrado. Poderia ser um olhar, um grito diferente, sons pouco habituais. Cronometrando o tempo infinitesimal que dedicava a mais ou a menos no pareamento, na pintura. Tudo importava. Tudo era traço de luz de uma alvorada que não se repetia no dia seguinte.

Cada vez que o sinal de entrada tocava, a rotina - que foi construída paulatinamente e constantemente atualizada - servia de parâmetro para trabalhar. A escola, os funcionários, os colegas de classe eram todos iguais, e as atividades variavam dentro de certa lógica. Criava-se um óbvio no trabalho docente, na relação entre mediador e mediado.

Os dias letivos iam e voltavam como batidas de um pêndulo que se move em uma repetiçáo tão invariável que o faz parecer 
inerte. Onde está o movimento? O ritmo? Mediador e mediado. Existe um "entre", que é pouco aparente, e vislumbrar essa quimera era um alvo diário na busca de conhecer o rapaz na sutileza dos detalhes, enquanto dava conta do currículo (adjuvante secundário) que fora discutido para ele antes de mim - mas que precisei incorporar à rotina - e aparecia na forma de planejamento.

Os rótulos e os estereótipos montam um espectro autista, e o trabalho pedagógico pauta-se nele desde a tenra idade para muitas crianças. Com o rapaz não era diferente. Derrubá-los é como derrotar gigantes disfarçados de moinhos, tal como almejava Don Quixote. Contudo, às vezes, qualquer um se sente como Rocinante, seu reles cavalo subalterno: "- Não quero deste trigo de sempre, o feno há de ser o que te faz mover, daí vem a energia para pelejar! É uma luta contra o instituído paralisante, raiz do que é cômodo e exponencial do medo, que é um lugar. Cômodo para se acomodar, porque nele náo precisa se mexer".

O rapaz tem algumas estereotipias: anda para lá e para cá. Lambe as mãos. Também bate, morde a si e aos outros. Essa é a sua linguagem? Parecia que o lugar do repudiável já estava bem definido e era dele que queria sair. Se qualquer criança faz bagunça, bate, empurra ou se suja, por qual motivo isso era táo danoso e grave para o rapaz autista?

A "importância de uma coisa não se mede com fita métrica nem com balanças nem barômetros etc. Que a importância de uma coisa há que ser medida pelo encantamento que a coisa produza em nós" (Barros, 2003, p. 9). O rapaz tinha muitas virtudes e talentos que nem sempre eram considerados e que eram possíveis de serem sublinhados.

Aquele que bate também sorri bastante, alegra-se ao caminhar, gosta de abraçar e fazer carinho nas pessoas. A linha do deslocamento: encontrar encantamento em muitos gestos do estudante mediado. Ou seja, mostrar aos colegas da turma que poderiam 
interagir como ele sem medo, que aprenderia a lanchar com certa autonomia, entre outras coisas...

Fazia pequenos passeios, mesmo que pelos corredores da escola, dizendo aonde estávamos indo. Por vezes, visitávamos algum colega de outra turma, subindo e descendo escadas, de mãos dadas ou não, enquanto, durante os trajetos, nomeava as pessoas e os lugares. Isso foi transformando o andar para lá e para cá despretensioso e frenético, mudando sua relação com todos na escola.

\begin{abstract}
'Quem é você?', perguntou a Lagarta. Não era uma maneira encorajadora de iniciar uma conversa. Alice retrucou, bastante timidamente: 'Eu eu não sei muito bem, Senhora, no presente momento - pelo menos eu sei quem eu era quando levantei esta manhã, mas acho que tenho mudado muitas vezes desde entâo' (Carrol, 2005, p. 50).
\end{abstract}

A lagarta questionou quem era Alice, e a menina deslocou a pergunta por meio da resposta. Quem está mudando afinal? O menino, seu pedagogo, a turma em relação a ele, os funcionários? Quantas mudanças cercam a escola enquanto, no decorrer dos dias, ele avança em descobertas, frustraçôes e na limitação de rotinas? Tentava tornar fantásticas suas possibilidades. Constatava que nem tudo é possível, mas fazia de cada atividade regular uma maneira de aprender como o mediador pode ensinar o mediado. E, por vezes, quando nada saía como planejado, havia inúmeros caminhos a seguir, sempre valiosos. Isso era profícuo, como um dueto ensaiado dia após dias para que, tocado com emoção, faça audíveis notas improvisadas.

\title{
Entre algumas práticas...
}

A palavra "entre" não é simplesmente um termo ingênuo ou uma preposição que indica o espaço de um lugar a outro. É essencial por indicar uma relação... (DIAS, 20I4, p. 34) 
O "entre", aqui, é uma relação singular que define o binômio mediador-mediado, mas não se encerra nele, superando uma simples dicotomia. É a interseçâo entre dois modos de vida e de perceber a si e ao mundo, no território comum da escola, que tanto projeta os problemas familiares quanto permite encontros. Cria uma infinidade de redes e conexóes que se articulam e permitem o enquadramento do sujeito, assim como trazem a possibilidade da invençáo do novo e a fuga de padróes.

Entre o discente que mediei, um ano letivo se passou. Muitas coisas aprendi acerca dele e a sua confiança conquistei. A recíproca foi verdadeira, entre nós, família, turma, professora, coordenação, supervisão, colegas da escola. O "entre" é uma ponte vazada, que atravessa dois eixos em constante movimento e que leva a diversos caminhos.

Comentarei algumas linhas das rotas que segui em algumas situaçóes específicas. Não é o objetivo criar um tratado a respeito do autismo, mas, sob o agenciamento com a literatura, os diários de campo, a produçáo de conhecimento que acessei acerca do espectro autista, minha supervisão e coordenação pedagógica, família e turma, produzir um relato.

Agenciar não é fazer pelo outro, em lugar do outro, como imediatamente se seria levado a pensar. Não se trata da distância entre o que produz e o que, por demanda do produtor, viabiliza as condiçóes materiais de produção e de colocação do produto em circulação. Esta é a visão de mercado [...] (Souza, 20I2, p. 29).

Por conseguinte,

[...] o verbete agenciar, aqui considerado inevitavelmente no escopo da filosofia deleuziana, remete a um processo de criação, seja artístico ou científico. Certamente a heterogeneidade das instâncias - traço constante na noção 
mercadológica de agência - entra nesse outro modo de formular o conceito. No agenciar, múltiplos agentes entram em ação (Souza, 20I2, p. 29).

Até o grito do menino era produtor de realidade. Tudo ao seu redor encampava o tempo e o espaço escolar. Trazer à tona minhas impressôes e apostas na abordagem em situaçóes específicas - poderiam ser outras -, como professor mediador, é um agenciamento com minha vida entregue, e imbrica para tornar a estadia de seu aluno mais leve, fluida e qualificada.

Durante muitas semanas, era possível que o menino estivesse mais inquieto em razão da mudança do medicamento que lhe era atribuído ou qualquer outra coisa. Porém, o trabalho seguia, e não deixávamos de tentar cumprir a rotina: com a pintura, o uso de cores quentes ou a realização do movimento da primeira letra do nome dele com o dedo sobre a massinha. Esta, na época, custounos muito, e somente depois de dias logramos êxito. O que não é entediante para ele? Ou melhor, o que lhe é interessante?

A mediaçáo é um incessante jogo de forças no qual a atençáo deve funcionar instintivamente para fazer com que o dito mediado atente-se nas atividades. Em outros termos, esforço e persistência para sempre recomeçar um trabalho educativo. Sua recusa diz respeito ao fato de que muitas coisas não fazem sentido, e, como o profissional, mais que sugere, define o que é bom, e, em nome disso, age.

É comum afirmar que o autista utiliza objetos de forma não convencional. Por horas, isso é verdade, às vezes, não. Houve uma semana em que o rapaz mediado mostrou o quanto lançava mão de coisas de acordo com o que lhe era interessante. Náo podia deixar a argila para ele, porque ele era tátil e, sendo assim, fazia questáo de tocar em tudo. E também palatal, porque levava à boca aquilo que experimentava com a palma das mãos e a ponta dos dedos. Ou seria um tique de alguém que quer ver as mãos limpas? Mas, se ele curtia esse material, por que privá-lo? 
Já que ele não acompanhava o conteúdo como a turma, a oportunidade maior de interaçáo com os colegas era, além do recreio, nas contaçôes de histórias, na aula de música e artes. Minha presença com o rapaz transmitia confiança aos estudantes da turma para caminhar com ele, lavar sua mão na pia da sala de artes ou brincar. Às vezes, íamos para a sala de recursos ou à quadra com um desses colegas para realizar alguma atividade. De todo jeito, tudo era bastante mediado por mim.

A direção das condutas tenta sempre dar conta de uma suposta autonomia, mesmo que ela venha por meio de portos seguros. Ou seja, oportunizar liberdade dentro de um espaço vigiado como a escola é contraditoriamente pujante. Seu riso, muitas vezes fácil, demostrava como destrinchávamos, naquele lugar de sempre, caminhos e significaçôes interessantes para nós, e isso ressoava e contagiava a todos.

Ribetto (20I4) trata o riso como um analisador do cotidiano escolar, um acontecimento que pode estar "relacionado ao pensamento humano" (Ribetto, 20I4, p. 84). A análise da autora converge e intercede hoje com o que observei durante a mediação relatada aqui. A meu ver, o riso do menino era uma expressáo sincera de que estava satisfeito consigo mesmo ou com o outro. As pedagogias que o cercavam não visavam ao riso, mas ele acabava por acontecer, imprevisivelmente e carregado de signos de um caminho franco não subalternizado. Em suma, o riso "não só como gesto de diversão, mas como desafio ao saber sério do mundo oficial, tido como verdade absoluta" (Ribetto, 20I4, p. 84).

Com todos os saberes técnicos e já estabelecidos acerca do rapaz, o agenciamento que compunha mediador e mediado produzia outra verdade que náo desqualificava o estabelecido, mas disputava sentido. Nas horas que ali ficávamos, eu era desafiado a continuar anotando seus gestos na busca de criar sinapses, conexôes entre aquilo que fazia e o que queria, ou de que modo que- 
ria estabelecer comunicação comigo e os outros. Não era uma pretensiosa interpretaçáo de tudo o que fazia, mas a experimentaçáo da vida que acontecia entre o menino, a turma, o espaço da escola, eu, sua chegada, saída...

Como pode acontecer com qualquer criança, um dia o rapaz estava com muita dor de barriga e não conseguia se conter. Em algum dia era possível que ele já chegasse "sujo”. Quando isso acontecia, dava um banho nele. A hora desse asseio era parte da rotina. Ainda que seja corriqueiro na educação infantil banhar as crianças, o menino, que estava alguns anos à frente, precisava aprender a organizar-se no banheiro, e tirávamos um tempo para isso. Cantava músicas, mostrava fotos do que devia fazer. Nesse caso específico, um simples banho era uma tarefa elaborada e complexa.

$\mathrm{O}$ incomum era a necessidade de limpá-lo várias vezes no mesmo dia. Já acontecera de, somente ao final da aula, saber que um remédio fora o responsável por aquilo. Sendo assim, julgava importante que qualquer alteração na sua rotina ou qualquer situação incomum fosse informada, para que eu me adaptasse melhor às situaçóes. Mais adiante, ficava pensando: que mais eu faria com uma criança com dor de barriga? Mandaria de volta para casa? Se estar na escola interagindo com os colegas o deixava risonho, valeria a pena insistir com o menino na escola?

Por outro lado, diversas vezes, o menino fazia de tudo para me mostrar que não estava bem. É uma questão de perceber os sinais que ele dá com uma expressão apreensiva na face: puxando-me pela camisa e negando-se mais que o habitual a fazer as atividades. Isso me deixava feliz: a condição dele engendrava a produção de códigos e sinais que configuravam uma espécie de linguagem, ao menos nesse ponto, entre ele e meu esforço em perceber seus gestos.

Ainda cartografando os relatórios: o carinho e o afeto não é uma premissa para o fazer profissional, mas um esteio para o fazer 
nas relaçóes humanas. Mantinha a paciência, deslocando seus gritos com brincadeiras, na esperança de que ele entenderia.

Sublinho que educar carrega, na etimologia da palavra, a passagem forçada a algum lugar. Denota uma normalização de comportamentos que se almeja, e o problema que cortou transversalmente a experiência exposta aqui era: Como tornar a mediação menos violenta, mais poética, reconhecendo no outro aquilo que também somos nós? Ou aquilo que não somos, ou seja, suas diferenças?

Quando estava com "os ouvidos abertos", mesmo na tribulaçáo de seus rompantes, subia a escada, descia quando chamava e bebia água espontaneamente no bebedouro - aprender a apertar um botão é um aprendizado para uma criança com alguma hipotonia nas mãos. Saía da sala quando queria ir ao banheiro e parava em frente ao portão de saída quando a escola estava enfadonha... Tudo isso conquistávamos, ele e eu.

Vez por outra, era surpreendido com alguma informação - assertiva ou não - das pessoas que o conheciam há mais tempo do que eu. Daí, começava a registrar também. Mediar significa intervir incessantemente. Mesmo quando se estamos parados, olhando o estudante fazer algo, estamos intervindo. O marasmo e a apatia são refratários ao agenciamento, o que potencializa a vida além dos muros da escola.

Concluía sempre o óbvio: sua humanidade. Irritação e ansiedade compartilhadas com todos os que se intitulam normais, regulares, e dormem com o Rivotril, seguram-se na Neosaldina e brigam com quem gostam por motivos que nem se lembram ao final do dia. Uma crítica que faço e que seria oca, se desconsiderarmos que a valia dos saberes de vanguarda funcionam, e não necessariamente precisam ser medicalizadoras de todos os aspectos da existência e formação humana, que também passam pela escola. 
Não existe fórmula, ainda que se elaborem verdades acerca do objeto e da identidade "autista". Ler, conhecer e estudar dizem respeito mais à apropriação de um campo semântico de ideias do que da receita de uma ação. A vida pulsa, faz movimento. Nela trememos, sorrimos, encaramos, enfezamo-nos. Teoria é prática, formação permanente de uma experiência que nos atravessa e forja, como se fôssemos, ao trançar das linhas, o próprio tear, e este, seus braços, por meio do qual o fazer pedagógico se cria e se transforma.

Por essa razão, quebrei a rigidez das categorizaçóes por meio de um procedimento de escrita contínuo e regular. Trabalhoso, nunca frígido, mas estimulado por uma processualidade ininterrupta e cansativa. Isto fez do que estava posto o oposto. Uma quimera que se via trancada. Registos de práticas a serem cartografadas, modos de vida desenhados por linhas de subjetividade, na simplicidade dos gestos e risos de todo o dia. "Estar entre vírgulas, pode ser aposto, mas eu aposto o oposto... que vou cativar a todos, sendo apenas um sujeito simples!" (Sintaxe à Vontade - O Teatro Mágico).

\section{Referências}

BARROS, Manoel de. Memórias inventadas: a infância. São Paulo: Planeta, 2003.

CABRAL, Maria do Carmo Carvalho. Encontros que nos movem: a leitura como experiência inventiva (tese). Universidade Federal do Rio de Janeiro, 2006.

CARROL, Lewis. Alice no pais das maravilhas. São Paulo: Martin Claret, 2005.

COLASSANTI, Marina. A moça tecelã. Disponível em: http://cocminas. com.br/arquivos/file/A\%2oMoCa\%2oTecelA\%2opdf.pdf. Acesso em: is mai. 20I4.

COSTA, Luis Artur et al.. "Cartografar". In FONSECA, Tania Mara Galli et al. (orgs.). Pesquisar na diferença: um abecedário. Porto Alegre: Sulina, 2012. 
DELEUZE, Gilles. “¿Que és un dispositivo?”. Michel Foucault, filósofo. Trad. Wanderson Flor do Nascimento. Barcelona: Gedisa, I990. e GUATTARI, Félix. Mil Platôs. São Paulo: Ed. 34, 20II, v. I.

DIAS, Rosimeri de Oliveira. "Trajetórias poéticas por entre formação, arte e escola básica”. In RIBETTO, Anelice (org.). Políticas, poéticas e práticas pedagógicas (com minúsculas). Rio de Janeiro: Lamparina, FAPERJ, 2014.

NASCIMENTO, Maria Lívia e SCHEINVAR, Estela. "Interface: o conselho tutelar como campo de intervenção". In e (orgs.). Intervenção socioanalítica em conselhos tutelares. Rio de Janeiro: Lamparina, 2010. RIBETTO, Anelice. "Dos saberes risíveis aos saberes menores na educação”. In (org.). Políticas, poéticas e práticas pedagógicas (com minúsculas). Rio de Janeiro: Lamparina, FAPERJ, 2014.

SÁVIO, Luan. Oficina de texto, cartografia e politicas de formaçâo de professores (monografia). Universidade do Estado do Rio de Janeiro, 2012.

SOUZA, Pedro de. "Agenciar". In FONSECA, Tania Mara Galli et al. (orgs.). Pesquisar na diferença: um abecedário. Porto Alegre: Sulina, 2012. 